\title{
MEDIDAS RADIOMÉTRICAS EM CASAS DE VEGETAÇÃO COM COBERTURA PLÁSTICA NA REGIÃO DE CAMPINẢS - SP
}

\author{
EDILSON COSTA ${ }^{1}$, PAULO A. M. LEAL ${ }^{2}$
}

\begin{abstract}
RESUMO: Com o objetivo de caracterizar as relações e alterações radiométricas em três casas de vegetação, cobertas com filme transparente de polietileno de baixa densidade (PEBD) de camada simples com $150 \mu \mathrm{m}$ de espessura, tratado contra raios ultravioleta, sob ambientes distintos, foram realizados os experimentos durante o cultivo hidropônico de alface, cultivar Vera, na região de Campinas - SP, em diferentes períodos do ano, visando ao uso de dados experimentais de postos meteorológicos em substituição à necessidade de adquirir equipamentos de radiação para medições internas. As casas de vegetação eram de estrutura metálica de aço, de forma e volume idênticos. Coletaram-se a radiação solar global interna e externa (RSGI e RSGE, W m ${ }^{-2}$ ), a radiação fotossinteticamente ativa (RFA, $\mu \mathrm{mol} \mathrm{m} \mathrm{m}^{-2} \mathrm{~s}^{-1}$ ) e a radiação ultravioleta, em 254; 312 e $365 \mathrm{~nm}$ (RUV, $\mathrm{W} \mathrm{m}^{-2}$ ). Os resultados mostraram que as equações de regressão linear são estimativas aceitáveis na obtenção da radiação fotossinteticamente ativa em função da radiação solar global externa. Em ambientes fechados e climatizados, existe maior correlação entre a radiação fotossinteticamente ativa e a radiação solar global externa. A orientação das casas de vegetação não climatizadas não influencia no espalhamento interno da radiação fotossinteticamente ativa.
\end{abstract}

PALAVRAS-CHAVE: ambiente protegido, climatização, polietileno de baixa densidade, radiação solar.

\section{RADIOMETRIC MEASUREMENT OF GREENHOUSES WITH PLASTIC COVER AT CAMPINAS REGION- SP}

\begin{abstract}
The objective of this study was to characterize the radiometric relationship and changing in three greenhouses covered with transparent low density polyethylene film (PEBD) with a $150 \mu \mathrm{m}$ single layer of low density polyethylene film, treated with compounds that inhibit rapid degradation by ultraviolet radiation, under effects of different environments. The experiments were conducted during hydroponics lettuce production of Vera variety at Campinas region-SP in different periods of the year, aiming the use of experimental data from meteorological stations in substitution of the needs to pursue radiometric equipments for internal measurements. Three identical greenhouses, in shape and volume, with steel metal structure were used. Data of internal and external global solar radiation (RSGI and RSGE, $\mathrm{W} \mathrm{m}^{2}$ ), photosynthetically active radiation (RFA, $\mu \mathrm{mol} \mathrm{m} \mathrm{m}^{-2}$ ), and ultraviolet radiation in 254; 312 e $365 \mathrm{~nm}\left(\mathrm{RUV}, \mathrm{W} \mathrm{m}^{-2}\right.$ ) were collected. The results showed that the linear regression equations are acceptable to estimate the photosynthetically active radiation based on the external global solar radiation. Closed acclimatized greenhouses show better statistical correlation between the photosynthetically active radiation and the external global solar radiation. The orientation of non acclimatized greenhouses does not influence the internal scattering of photosynthetically active radiation.
\end{abstract}

KEYWORDS: Protected environment, climatization, low density polyethylene, solar radiation.

\footnotetext{
${ }^{1}$ Prof. Dr., Universidade Estadual de Mato Grosso do Sul (UEMS), Unidade Universitária de Aquidauana - MS, mestrine@uems.br.

${ }^{2}$ Prof. Titular, FEAGRI/UNICAMP, Campinas - SP, pamleal@ feagri.unicamp.br.

Recebido pelo Conselho Editorial em: 1-2-2010

Aprovado pelo Conselho Editorial em: 13-4-2011
}

Eng. Agríc., Jaboticabal, v.31, n.3, p.448-457, maio./jun. 2011 


\section{INTRODUÇÃO}

Existem inúmeras possibilidades de constituição dos ambientes protegidos para a produção vegetal intensiva, com diversas configurações, vários materiais estruturais, diferentes tipos de materiais de cobertura e de proteção lateral, apresentando custos diferenciados pelas tecnologias empregadas, especialmente em ambiente climatizado, que é realizado, geralmente, por sistemas de resfriamento evaporativo do ar.

$\mathrm{O}$ uso de filme de polietileno de baixa densidade (PEBD), como cobertura e fechamento de casas de vegetação, tem como objetivos a proteção das plantas contra intempéries, aquecimento do ambiente interno no inverno, principalmente na região Sul, atenuação da incidência direta dos raios solares sobre as plantas, sendo um procedimento difundido no Brasil (PEZZOPANE et al., 2004). Para ampliar a via útil média do filme, tratamentos químicos são utilizados para minimizar a degradação pelos raios ultravioleta.

As alterações microclimáticas no interior de casas de vegetação, provocadas pela utilização do polietileno, modificando a temperatura do ar, a umidade relativa do ar e a radiação solar, influenciam no desenvolvimento e no crescimento vegetal, e estes são dependentes da intensidade, qualidade e duração da radiação solar (BECKMANN et al., 2006; SCARANARI et al., 2008). Estas alterações interferem na fisiologia das plantas (CHAVARRIA et al., 2009), minimizam a incidência de doenças fúngicas e a substancial aplicação de defensivos (CHAVARRIA et al., 2007). Em vinhedos, cobertos com filme apenas nas fileiras, CARDOSO et al. (2008) verificaram redução na demanda evaporativa.

A radiação solar é a componente principal na alteração interna do ambiente de cultivo e, sendo interceptada pela cobertura vegetal, pode ser absorvida, refletida e transmitida em proporções variáveis, influenciando no crescimento e desenvolvimento da planta em função da intensidade, qualidade e duração (BECKMANN et al., 2006). CHAVARRIA et al. (2009) verificaram em cultivo de vinhedo que o filme de polietileno, apenas nas fileiras de plantas, interfere na qualidade da radiação e reduz a irradiância na faixa do ultravioleta e a razão entre vermelho e vermelho distante. COSTA \& LEAL (2009) relatam que, com o tempo, as impurezas impregnadas no filme diminuem as relações entre as radiações global interna e externa e entre as radiações ultravioleta.

A radiação fotossinteticamente ativa (RFA), componente da radiação global, compreende a faixa de 400 a 700 nanômetros. OLIVEIRA et al. (2008) relatam que, em plantas de curauá (Ananas comosus var. erectifolius), níveis de $100 \%$ de RFA aumentam a espessura cuticular, e níveis de $54 \%$ promovem mais feixes fibrosos. Por ser a radiação que excita as moléculas da clorofila, apresenta importância em estudos da taxa fotossintética e condutância estomatal (FRISINA et al., 2003), além da modelagem de crescimento (FONSECA et al., 2006), na estimativa da fotossíntese (STEIDLE NETO et al., 2006) e acúmulo de biomassa (MOREIRA et al., 2005). Contudo, poucos sensores da radiação fotossinteticamente ativa estão disponíveis nos institutos de pesquisa ou mesmo em universidades; logo, a modelagem e as estimativas da radiação solar global direta e difusa, seus respectivos componentes, como radiação ultravioleta, radiação fotossinteticamente ativa, infravermelho próximo e infravermelho são importantes para se conduzir pesquisas em ambientes de cultivo protegido (BORGES et al., 2010; CODATO et al., 2008; ESCOBEDO et al., 2006a; ESCOBEDO et al., 2006b, ESCOBEDO et al., 2009; FRISINA et al., 2003). Já o conhecimento da radiação solar direta na incidência $(0,285$ a 4,0mm), por meio de séries temporais e de modelos de estimativa, permite conhecer a disponibilidade energética diurna e anual em função do tempo, sem necessidade de outros instrumentos de medida; todavia, exigem que a medida da radiação direta na incidência seja realizada de rotina, por um tempo acima dos cinco anos (GOMES et al., 2006). Portanto, determinar equações de regressão linear simples que estimem a RFA no interior da estufa de polietileno climatizada e não climatizada, a partir de medições externas da RSG e da RFA, é de suma importância para reduzir o número de equipamentos necessários. Estimativas da RFA externas aos ambientes protegidos, utilizando simulação estocástica, foram realizadas por 
MARTIN et al. (2007), assim como estudos sobre a radiação global, RFA e insolação (MARTIN et al., 2008).

O presente trabalho teve como objetivos caracterizar as relações e as alterações radiométricas em casas de vegetação provocadas pela utilização do PEBD transparente, na região de Campinas SP, em diferentes períodos do ano, visando ao uso de dados experimentais de postos meteorológicos em substituição à necessidade de adquirir equipamentos de radiação para medições internas.

\section{MATERIAL E MÉTODOS}

Esta pesquisa foi conduzida em três casas de vegetação tipo "Capela", de estrutura metálica e duas águas, com dimensões de 6,5 m de largura, 11,0 m de comprimento, 3,0 $\mathrm{m}$ de pé-direito, coberta com filme transparente de PEBD com $150 \mu \mathrm{m}$ de espessura, tratado contra raios ultravioleta.

No campo experimental da Faculdade de Engenharia Agrícola (FEAGRI) da Universidade Estadual de Campinas (UNICAMP), Campinas - SP (22 $48^{\prime} 57^{\prime \prime}$ sul, $47^{\circ} 03^{\prime} 33^{\prime \prime}$ oeste e altitude média de $640 \mathrm{~m}$ ), no período de março de 2000 a janeiro de 2001. O clima da região enquadra-se no subgrupo Cwa, segundo a classificação internacional de Köeppen, mesotérmico de inverno seco, com temperatura anual de $21,0^{\circ} \mathrm{C}$ (média no mês mais frio de $18^{\circ} \mathrm{C}$ e no mês mais quente de $24^{\circ} \mathrm{C}$ ) e precipitação média anual de $1.372 \mathrm{~mm}$. Utilizaram-se casas de vegetação com ambientes distintos. $\mathrm{O}$ ambiente A1 era uma casa de vegetação orientada leste-oeste com paredes frontais fechadas com o mesmo plástico da cobertura e com as duas laterais abertas. $\mathrm{O}$ ambiente A2 era uma casa de vegetação orientada norte-sul com as mesmas características das paredes do ambiente A1, e o ambiente A3 era uma casa de vegetação orientada norte-sul, mas, por possuir resfriamento evaporativo do ar (climatizada), do tipo meio poroso e exaustor, apresentava todas as paredes fechadas com o mesmo plástico da cobertura.

Foram feitas medições de radiação solar global interna (RSGI), externa (RSGE), fotossinteticamente ativa (RFA) e ultravioleta (RUV), em 254; 312 e $365 \mathrm{~nm}$. A radiação solar global (RSG) foi medida por piranômetros (Li-200SZ) calibrados e com resolução de 0,5\%, instalados apenas na casa de vegetação A3, sendo internamente (RSGI) a 0,30 m abaixo do filme de cobertura, e externamente (RSGE), sobre o PEBD na cumeeira. A radiação fotossinteticamente ativa (RFA) foi medida através de sensores quantum (Li 190SA) com resolução de $0,5 \%$, instalados em duas alturas: $0,70 \mathrm{~m}(\mathrm{I}=$ sensor inferior $)$ e $1,37 \mathrm{~m}(\mathrm{~S}=$ sensor superior $)$ próximos a uma das bancadas, nos três ambientes de cultivo. Para caracterização de RFA, considerou-se a média dos dois sensores. Os piranômetros e os sensores quantum estavam conectados a um sistema de aquisição de dados (Li-1.400) que armazenavam os dados diariamente, de hora em hora, entre 8 e 16h (horário local).

A radiação ultravioleta (RUV) foi medida por sensores Cole-Parmer para os comprimentos de ondas de 254; 312 e $365 \mathrm{~nm}$ às $12 \mathrm{~h}$ (horário local). Os sensores foram instalados a uma altura de $1,37 \mathrm{~m}$, no ambiente $\mathrm{A} 3$ e externamente, devido à restrição de material. Os dados foram coletados por um radiômetro portátil Cole Parmer VLX 3W.

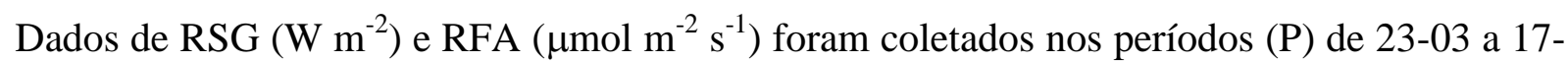
04 (P1), de 27-05 a 29-06 (P2), de 14-07 a 22-08 (P3) e de 16-09 a 02-10 (P4). Enquanto RUV (W $\mathrm{m}^{-2}$ ) foi medida nos períodos de 27-03 a 17-04 (P1), 26-05 a 29-06 (P2), 14-07 a 20-08 (P3), de 0809 a 02-10 (P4) e de 12-12 a 10-01/01 (P5). Não foram medidas RFA e RSG no período P5, devido a problemas no sistema de aquisição de dados (Li-1.400).

Foram comparados os quatro períodos de medição (quatro tratamentos) avaliando as RFAs em cada ambiente de cultivo, e as RSGs. Também foram comparados os três ambientes de cultivo (três tratamentos) avaliando as RFAs em cada período, utilizando um delineamento inteiramente casualizado, sendo as repetições a média diária das $8 \mathrm{~h}$ às $16 \mathrm{~h}$ (Tabela 1). Os dados foram submetidos à análise de variância, e as médias, ao teste de Tukey, em nível de 5\% de probabilidade. 
As análises foram realizadas através do programa computacional ESTAT (UNESP/FCAVJ, 1994). Foram feitas análises de regressão das RFAs de cada ambiente de cultivo e da RSGI das médias diárias em função da RSGE, utilizando o software Excel.

\section{RESULTADOS E DISCUSSÃO}

Na casa de vegetação sem climatização (A1), que se encontrava no sentido leste-oeste, no período de dezesseis de setembro a dois de outubro (P4), houve maior disponibilidade de radiação fotossinteticamente ativa que nos demais períodos. Para os demais ambientes, o período P4 não diferiu do período P1. A RSGE foi maior no período P4. No entanto, para a radiação global interna (RSGI), esse período foi similar ao P1 (Tabela 1). No período P4, ocorreu o equinócio, quando a declinação solar é zero, com o Sol percorrendo a linha do Equador e dirigindo-se para o Trópico de Capricórnio. Nessa condição, a maior incidência dos raios solares sobre os ambientes, possivelmente, promoveu maior espalhamento da radiação, ampliando a radiação global e difusa interna e aumentando a disponibilidade de RFA.

As relações RSGI/RSGE foram superiores aos valores encontrados em literatura, variando de $75,13 \%$ no período P3 até 83,20\% no período P4 (Tabela 1). Esses valores podem ter sido maiores devido à localização do sensor e às características do plástico, pois RICIERI \& ESCOBEDO (1996), para o PEBD de $150 \mu \mathrm{m}$, encontraram valores de 55,23\% na relação interna/externa em condições de céu coberto e de $65,34 \%$ em condições de céu limpo ou pequena difusividade. BECKMANN et al. (2006), em cultivo de tomate, em Pelotas-RS, encontraram $76 \%$.

Os ambientes de cultivo apresentaram RFA similares nos períodos P1, P2 e P4. No período P3, o ambiente A1 apresentou maior disponibilidade de RFA (Tabela 1). Observa-se que, praticamente, todos os ambientes tiveram o mesmo espalhamento da RFA na maioria dos períodos, permitindo maior penetração de radiação no dossel vegetativo e favorecendo o desenvolvimento da cultura, independentemente do período. No dossel vegetativo de videiras, houve redução da RFA através do filme (LULU et al., 2005) até 38\% (CHAVARRIA et al., 2009). Além do filme, SCARANARI et al. (2008) destacam que as telas vermelhas reduzem ainda mais a disponibilidade de RFA no interior de ambiente protegido.

A relação entre RUVI/RUVE, para os comprimentos de onda de $312 \mathrm{~nm}$ e $365 \mathrm{~nm}$, corresponderam a $39 \%$ e $43,4 \%$ dos valores externos, respectivamente, como média dos cinco períodos. Ao longo dos experimentos, a relação interna/externa foi diminuindo devido ao acúmulo de poeiras e desgaste do filme de polietileno (Tabela 1). CHAVARRIA et al. (2009) observaram que o filme intercepta cerca de 56\% de radiação ultravioleta, que é responsável pela degradação do mesmo e possui efeito nocivo às plantas.

A redução da camada de ozônio contribui para o aumento da radiação UV, especialmente a ultravioleta-B, que, em folhas de folhas de Arabidopsis thaliana, reduziram a área foliar, a massa fresca e seca, a densidade de tricomas na face adaxial e a densidade de estômatos na face abaxial da folha (BOEGER \& POULSON, 2006). Pelos resultados obtidos, o filme de polietileno atenua a radiação ultravioleta no interior do ambiente e propicia melhores condições de desenvolvimento vegetal. 
TABELA 1. Comparação entre radiação fotossinteticamente ativa (RFA) nos ambientes (A) e entre radiação solar global (RSG) média, das 8 às 16h, para diferentes períodos $(\mathrm{P})$ de março a outubro de 2000 , e entre radiação ultravioleta $(\mathrm{RUV})^{1}$ às $12 \mathrm{~h}$, para diferentes períodos (P) de março de 2000 a janeiro de 2001. Comparison among photosynthetically active radiations (RFA) in the environments (A), and among average solar global radiations (RSG) from 8AM to 4PM for different periods (P) from March through October of 2000, and among ultraviolet radiations (RUV) ${ }^{1}$ at noon time for different periods (P) from March of 2000 through January of 2001.

\begin{tabular}{|c|c|c|c|c|c|c|}
\hline & \multicolumn{2}{|c|}{$\mathrm{RSG}\left(\mathrm{W} \mathrm{m}^{-2}\right)$} & \multicolumn{4}{|c|}{$\operatorname{RFA}\left(\mu \mathrm{mol} \mathrm{m} \mathrm{m}^{-2}\right)$} \\
\hline Período & EX & IN & A1 & $\mathrm{A} 2$ & $\mathrm{~A} 3$ & $\mathrm{CV}(\%)$ \\
\hline $\mathrm{P} 1$ & $520,0 \mathrm{~b}$ & $431,4 \mathrm{a}$ & $676,1 \mathrm{bA}$ & $689,0 \mathrm{aA}$ & $728,0 \mathrm{aA}$ & 18,0 \\
\hline $\mathrm{P} 2$ & $399,9 \mathrm{c}$ & $315,3 \mathrm{~b}$ & $510,2 \mathrm{cA}$ & $520,9 \mathrm{bA}$ & $477,2 \mathrm{bA}$ & 17,5 \\
\hline $\mathrm{P} 3$ & $458,9 \mathrm{bc}$ & $344,7 \mathrm{~b}$ & $631,7 \mathrm{bA}$ & $513,7 \mathrm{bB}$ & $519,8 \mathrm{bB}$ & 26,7 \\
\hline $\mathrm{P} 4$ & $625,4 \mathrm{a}$ & $478,2 \mathrm{a}$ & $784,2 \mathrm{aA}$ & $704,0 \mathrm{aA}$ & $745,8 \mathrm{aA}$ & 14,6 \\
\hline \multirow[t]{2}{*}{ C.V. $(\%)$} & 21,9 & 24,1 & 20,4 & 20,7 & 20,3 & - \\
\hline & & \multicolumn{2}{|c|}{$\operatorname{RUV}\left(\mathrm{W} \mathrm{m}{ }^{-2}\right)-\mathrm{EX}$} & \multicolumn{3}{|c|}{$\operatorname{RUV}\left(\mathrm{W} \mathrm{m}^{-2}\right)-\mathrm{IN}$} \\
\hline \multicolumn{2}{|c|}{ Período } & $312 \mathrm{~nm}$ & $365 \mathrm{~nm}$ & \multicolumn{2}{|c|}{$312 \mathrm{~nm}$} & $365 \mathrm{~nm}$ \\
\hline \multicolumn{2}{|c|}{$\mathrm{P} 1$} & 2,15 & 16,47 & \multicolumn{2}{|c|}{0,88} & 7,55 \\
\hline \multicolumn{2}{|c|}{$\mathrm{P} 2$} & 0,88 & 9,45 & \multicolumn{2}{|c|}{0,37} & 4,17 \\
\hline \multicolumn{2}{|c|}{$\mathrm{P} 3$} & 1,01 & 10,40 & \multicolumn{2}{|c|}{0,42} & 4,71 \\
\hline \multicolumn{2}{|c|}{$\mathrm{P} 4$} & 2,35 & 17,27 & \multicolumn{2}{|c|}{0,80} & 6,58 \\
\hline \multicolumn{2}{|c|}{ P5 } & 3,57 & 17,48 & \multicolumn{2}{|c|}{1,33} & 6,67 \\
\hline \multicolumn{2}{|c|}{ Média } & 1,99 & 14,21 & \multicolumn{2}{|c|}{0,76} & 5,94 \\
\hline
\end{tabular}

${ }^{\mathrm{T}}$ Não se obtiveram valores diferentes de zero para $254 \mathrm{~nm}$. EX = Exterior; IN = Interior; CV = coeficiente de variação. * Médias seguidas de mesma letra, minúsculas nas colunas e maiúscula nas linhas, não diferem entre si, pelo teste de Tukey, a $5 \%$ de probabilidade.

O menor coeficiente de determinação $(0,896)$ entre RSGE e RSGI foi obtido no período (P2) de vinte e seis de maio a vinte e nove de junho (Figura 2), devido à declinação solar que atinge o máximo $\left(+23,45^{\circ}\right)$ no solstício de inverno. Nesse período, a localização da casa de vegetação, associada ao percurso do Sol e ao material da cobertura, pode ter promovido menor ângulo de incidência sobre o sensor, promovendo menor correlação. Nos demais períodos (P1, P3 e P4), a RSGI apresentou alta correlação com a radiação global externa (Figuras 1; 3 e 4).

RFA apresentou maior correlação com a RSGE no ambiente A3 (climatizado), nos quatro períodos. Como esse ambiente era climatizado e por apresentar-se totalmente fechado por filme de polietileno, promoveu maior espalhamento e distribuição da RFA, promovendo maior correlação com a RSGE (Figuras 1; 2; 3 e 4). STEIDLE NETO et al. (2006) relatam que, para estimar corretamente a radiação fotossinteticamente ativa em função da radiação global, deve-se considerar a variabilidade interanual desta relação, conforme trabalhado no presente experimento. Esta variabilidade sazonal expressa-se, também, no fluxo de calor latente e sensível e, consequentemente, no balanço de energia (ANDRADE et al., 2009), assim como na radiação solar global, onde SILVA JÚNIOR et al. (2006) observaram variação sazonal na ordem de $62 \%$.

Obtiveram-se equações que relacionam valores expressos em $\mu \mathrm{mol} \mathrm{s}^{-1} \mathrm{~m}^{-2} \mathrm{da} R F A$ e W m${ }^{-2} \mathrm{da}$ RSGE, com alto coeficiente de determinação (Figuras 1;2; 3 e 4). Assim sendo, é viável a estimativa da RFA de ambientes protegidos cobertos com PEBD a partir de dados que podem ser obtidos em estações meteorológicas.

Os ambientes não climatizados (A1 e A2), mesmo estando em posições perpendiculares, apresentaram coeficientes de determinação similares na maioria dos períodos, revelando que a posição da casa de vegetação não interfere no espalhamento interno da RFA (Figuras 1, 3 e 4). 


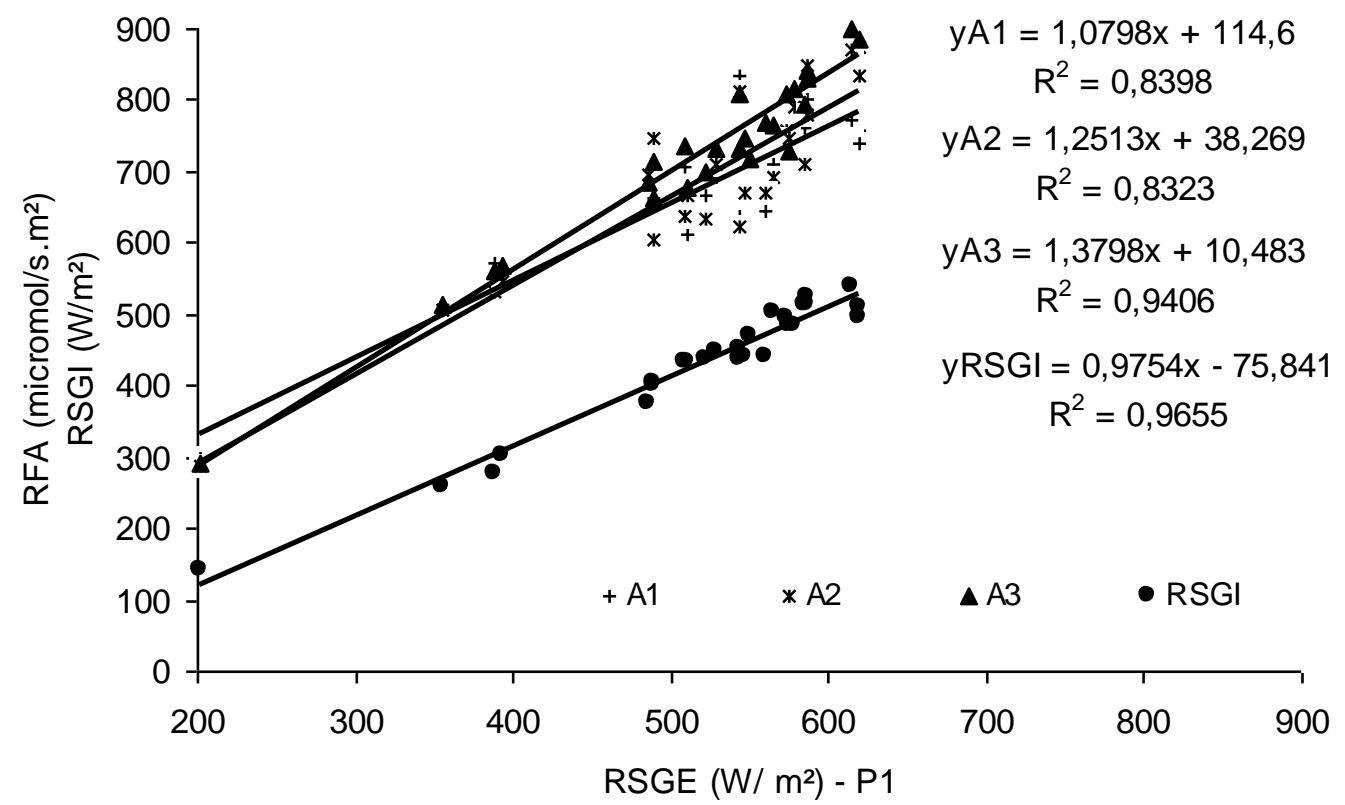

$\mathrm{A} 1$ = casa de vegetação com injeção aérea de $\mathrm{CO}_{2}$, sem resfriamento evaporativo do ar (leste-oeste). A2 = casa de vegetação com injeção de $\mathrm{CO}_{2}$, sem resfriamento evaporativo do ar (norte-sul). A3 = casa de vegetação com injeção de $\mathrm{CO} 2$ e resfriamento evaporativo do ar (norte-sul) (climatizada).

FIGURA 1. Relações entre radiações solar global externa (RSGE) e fotossinteticamente ativa (RFA) para os ambientes de cultivo, e radiações solar global externa e interna (RSGI), no período de outono (P1). Campinas-SP. 2000. Relations between external global solar radiation (RSGE) and photosynthetically active radiation (RFA) for the protected environments, and between external global solar radiation and internal global solar radiation (RSGI) in the autumn period (P1). Campinas, SP. 2000 .

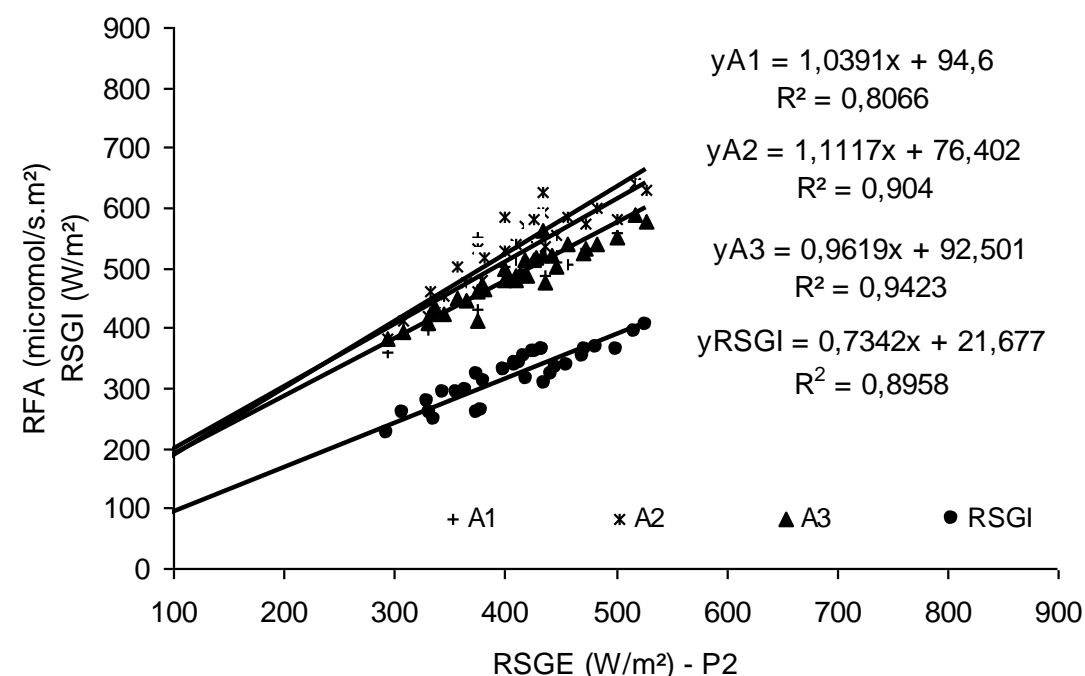

$\mathrm{A} 1$ = casa de vegetação com injeção aérea de $\mathrm{CO}_{2}$, sem resfriamento evaporativo do ar (leste-oeste). A2 = casa de vegetação com injeção de $\mathrm{CO}_{2}$, sem resfriamento evaporativo do ar (norte-sul). A3 = casa de vegetação com injeção de $\mathrm{CO} 2$ e resfriamento evaporativo do ar (norte-sul) (climatizada).

FIGURA 2. Relações entre radiações solar global externa (RSGE) e fotossinteticamente ativa (RFA) para os ambientes de cultivo, e radiações solar global externa e interna (RSGI), no período de outono/inverno (P2). Campinas-SP. 2000. Relation between external global solar radiation (RSGE) and photosynthetically active radiation (RFA) for the protected environments, and between external global solar radiation and internal global solar radiation (RSGI) in the autumn/winter period (P2). Campinas, SP. 2000. 


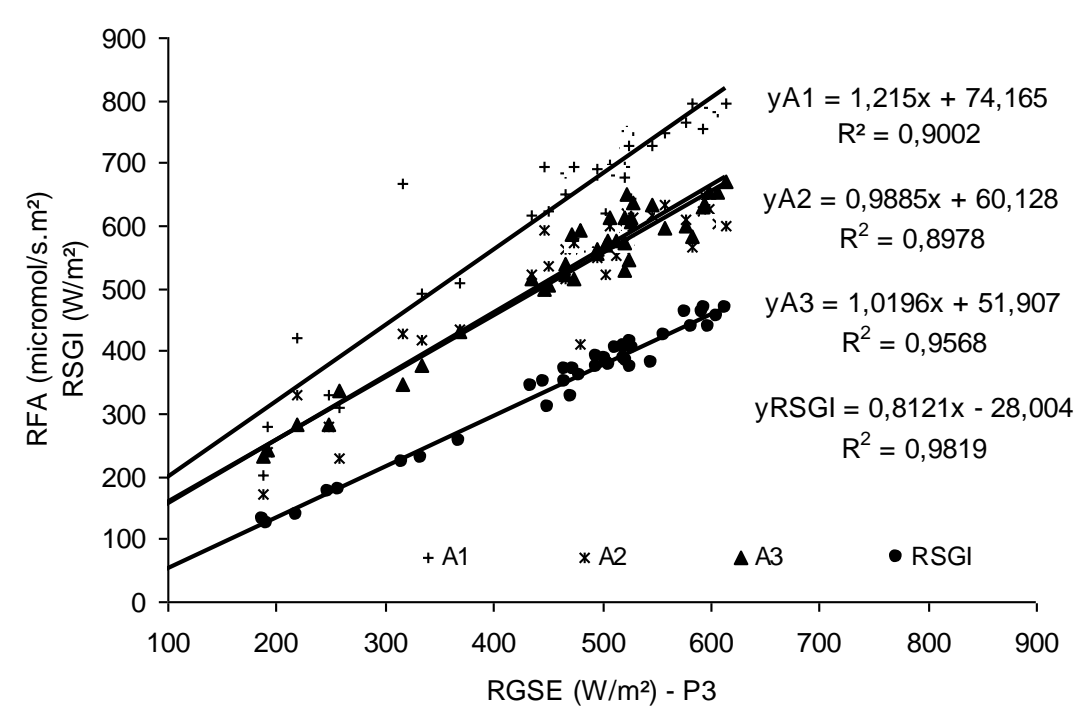

$\mathrm{A} 1$ = casa de vegetação com injeção aérea de $\mathrm{CO}_{2}$, sem resfriamento evaporativo do ar (leste-oeste). A2 = casa de vegetação com injeção de $\mathrm{CO}_{2}$, sem resfriamento evaporativo do ar (norte-sul). A3 = casa de vegetação com injeção de $\mathrm{CO} 2$ e resfriamento evaporativo do ar (norte-sul) (climatizada).

FIGURA 3. Relações entre radiações solar global externa (RSGE) e fotossinteticamente ativa (RFA) para os ambientes de cultivo, e radiações solar global externa e interna (RSGI), no período de inverno (P3). Campinas, SP. 2000. Relation between external global solar radiation (RSGE) and photosynthetically active radiation (RFA) for the protected environments, and between external global solar radiation and internal global solar radiation (RSGI) in the winter period (P3). Campinas, SP. 2000.

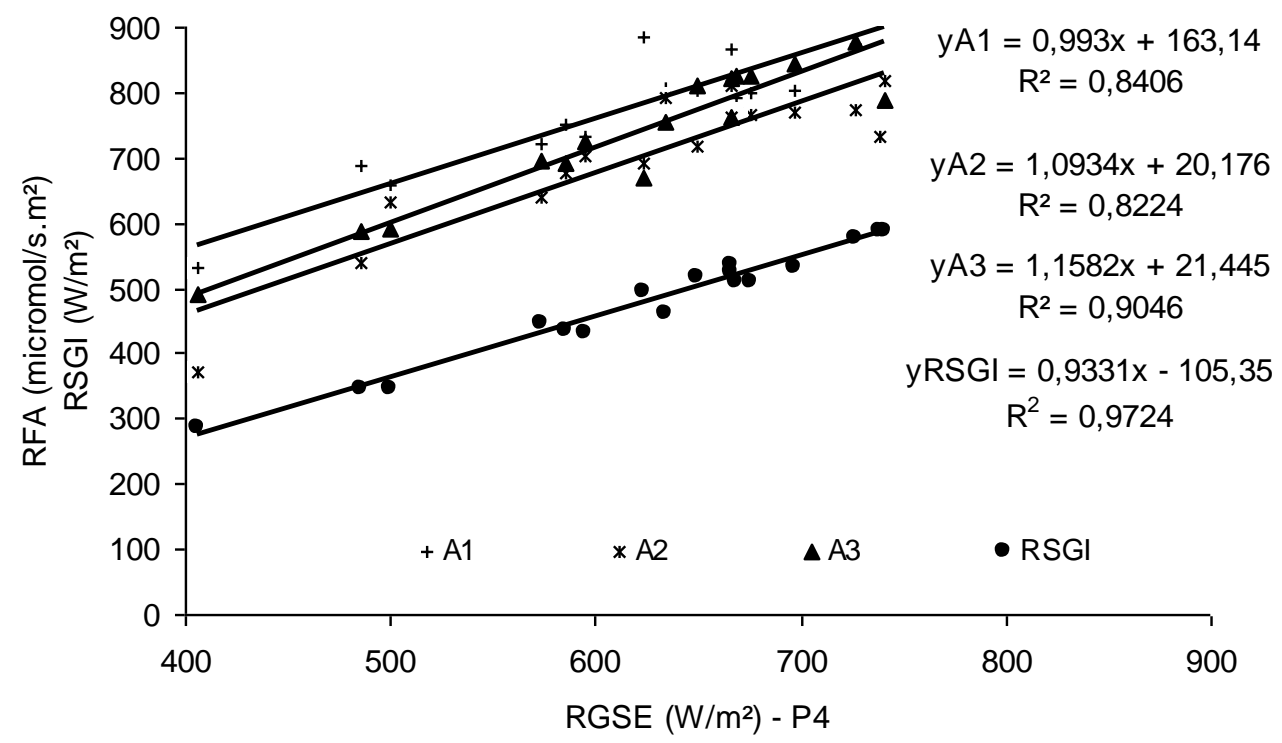

$\mathrm{A} 1$ = casa de vegetação com injeção aérea de $\mathrm{CO}_{2}$, sem resfriamento evaporativo do ar (leste-oeste). A2 = casa de vegetação com injeção de $\mathrm{CO}_{2}$, sem resfriamento evaporativo do ar (norte-sul). A3 = casa de vegetação com injeção de $\mathrm{CO} 2$ e resfriamento evaporativo do ar (norte-sul) (climatizada)

FIGURA 4. Relação entre radiações solar global externa (RSGE) e fotossinteticamente ativa (RFA) para os ambientes de cultivo, e radiações solar global externa e interna (RSGI), no período de inverno/primavera (P4). Campinas-SP. 2000. Relation between external global solar radiation (RSGE) and photosynthetically active radiation (RFA) for the protected environments, and between external global solar radiation and internal global solar radiation (RSGI) in the winter/spring period (P4). Campinas, SP. 2000. 
Altos coeficientes de determinação $(0,97$ e 0,98) foram encontrados por GALVANI et al. (2004), utilizando regressão linear entre RFA e RSGE, na estimativa sazonal da radiação fotossinteticamente ativa em São Paulo - SP, em diferentes estações do ano, ambas medidas em W $\mathrm{m}^{-2}$. Neste experimento, as correlações ficaram acima de 0,80. Provavelmente, maior período de coleta poderia apresentar maior coeficiente de determinação. ASSIS \& MENDEZ (1989) encontraram altas correlações em RFA $\left(\mathrm{E} \mathrm{m}^{-2}\right)$ e RSGE $\left(\mathrm{MJ} \mathrm{m}^{-2}\right)$, na ordem de 0,974, em 175 dias de coletas, de dezembro de 1982 a novembro de 1983, em Pelotas-RS.

\section{CONCLUSÕES}

Nas condições em que o experimento foi desenvolvido, houve relação entre a radiação global externa e fotossinteticamente ativa, o que permite utilizar dados obtidos em postos meteorológicos e as equações geradas, dispensando a aquisição de dispendiosos equipamentos para medidas internas.

Por haver maior espalhamento da radiação, em função da própria conformação do filme de polietileno na estrutura, o ambiente climatizado apresentou maior correlação entre a radiação fotossinteticamente ativa e a radiação solar global externa.

A radiação fotossinteticamente ativa, independemente da orientação das casas de vegetação cobertas com polietileno de baixa densidade transparente.

\section{AGRADECIMENTOS}

À FAPESP e CAPES, pelo financiamento da pesquisa e bolsa de mestrado, respectivamente.

\section{REFERÊNCIAS}

ANDRADE, N. L. R. de; AGUIAR, R. G.; SANCHES, L.; ALVES, E. C. R. de F.; NOGUEIRA, J. de S. Partição do saldo de radiação em áreas de floresta amazônica e floresta de transição amazônia-cerrado. Revista Brasileira de Meteorologia, São José dos Campos, v.24, n.3, 346-355, 2009.

ASSIS, F. N.; MENDEZ, M. E. G. Relação entre radiação fotossinteticamente ativa e radiação global. Pesquisa Agropecuária Brasileira, Brasília, v. 24, n. 7, p. 797- 800, 1989.

BECKMANN, M. Z.; DUARTE, G. R. B.; PAULA, V. A.; MENDEZ, M. E. G.; PEIL, R. M. N. Radiação solar em ambiente protegido cultivado com tomateiro nas estações verão-outono do Rio Grande do Sul. Ciência Rural, Santa Maria, v. 36, n. 1, p. 86-92, 2006.

BOEGER, M. R. T.; POULSON, M. Efeitos da radiação ultravioleta-B sobre a morfologia foliar de Arabidopsis thaliana (L.) Heynh. (Brassicaceae). Acta Botanica Brasílica, São Paulo, v. 20, n. 2, p. 329-338, 2006. Disponível em: <http://www.scielo.br/scielo.php?script=sci_arttext\&pid=S0102$33062006000200008 \& \operatorname{lng}=$ en\&nrm=iso>. Acesso em: 24 fev. 2010

BORGES, V. P.; OLIVEIRA, A. S. de; COELHO FILHO, M. A.; SILVA, T. S. M. da; PAMPONET, B. M. Avaliação de modelos de estimativa da radiação solar incidente em Cruz das Almas, Bahia. Revista Brasileira de. Engenharia Agrícola e Ambiental, Campina Grande, v.14, n.1, p.74-80, 2010.

CARDOSO, L. S.; BERGAMASCHI, H.; COMIRAN, F.; CHAVARRIA, G.; MARODIN, G. A. B.; DALMAGO, G. A.; SANTOS, H. P. dos; MANDELL, F. Alterações micrometeorológicas em vinhedos pelo uso de coberturas de plástico. Pesquisa Agropecuária Brasileira, Brasília, v. 43, n. 4, p. 441-447, 2008.

CHAVARRIA, G.; CARDOSO, L. S.; BERGAMASCH, H.; SANTOS, H. P. dos; MANDELLI, F.; MARODIN, G. A. B. Microclima de vinhedos sob cultivo protegido. Ciência Rural, Santa Maria, v. 19, n. 7, p. 2.029-2.034, 2009. 
CHAVARRIA, G.; SANTOS, H. P. dos; SÔNEGO, O. R.; MARODIN, G. A. B.; BERGAMASCH, H.; CARDOSO, L. S. Incidência de doenças e necessidade de controle em cultivo protegido de videira. Revista Brasileira de Fruticultura, Jaboticabal, v.29, n.3, p.477-482, 2007.

CODATO, G.; OLIVEIRA, A.P.; SOARES, J.; ESCOBEDO, J.F.; GOMES, E.N.; PAI, A.D. Global and diffuse solar irradiances in urban and rural areas in southeast of Brazil, Theoretical and Applied Climatology, Amsterdam, v. 93, n. 1-2, p. 57-73, 2008.

COSTA, E.; LEAL, P. A. M. Produção de alface hidropônica em três ambientes de cultivo. Engenharia Agrícola, Jaboticabal, v. 29, n. 3, p. 358-369, 2009.

ESCOBEDO, J.F.; GOMES, E.N.; OLIVEIRA, A.P.; SOARES, J. Radiações solares UV, PAR e IV: I - Estimativa em função da global. Avances en Energías Renovables y Medio Ambiente, Buenos Aires, v. 10, n.11, p.79-86, 2006a.

ESCOBEDO, J.F.; GOMES, E.N.; OLIVEIRA, A.P.; SOARES, J. Radiações solares UV, PAR e IV: II - Estimativa das frações em função de KT. Avances en Energías Renovables y Medio Ambiente, Buenos Aires, v. 10, n.11, p.87-94, $2006 \mathrm{~b}$.

ESCOBEDO, J. F.; GOMES, E. N.; OLIVEIRA, A. P.; SOARES, J. Modeling hourly and daily fractions of UV, PAR and NIR to global solar radiation under various sky conditions at Botucatu, Brazil. Applied Energy, Amsterdam, v. 86, n. 3, p. 299-309, março, 2009.

ESTAT. Sistema para análises estatísticas (v. 2.0). Jaboticabal: Departamento de Ciências Exatas, FCAV, UNESP, 1994.

FRISINA, V. A.; ESCOBEDO, J. F.; GOMES, E. N. Estimativa da radiação fotossinteticamente ativa (PAR) em estufa de polietileno. In: ENCONTRO DE ENERGIA NO MEIO RURAL, 3., 2003, Campinas. Proceedings... Disponível em:

<http://www.proceedings.scielo.br/scielo.php?script=sci_arttext\&pid=MSC0000000022000000200 056\&lng=en\&nrm=abn>. Acesso em: 30 maio 2009.

FONSECA, E. L. da; SILVEIRA, V. C. P.; SALOMONI, E. Eficiência de conversão da radiação fotossinteticamente ativa incidente em biomassa aérea da vegetação campestre natural no bioma Campos Sulinos do Brasil. Ciência Rural, Santa Maria, v. 36, n. 2, p. 656-659, 2006.

GALVANI, E.; SILVA, M. E. S.; GUILLAMUON, H. C. D. Estimativa sazonal da radiação fotossinteticamente ativa em São Paulo, SP. In: X REUNIÓN ARGENTINA Y IV LATINOAMERICANA DE AGROMETEOROLOGÍA, 2004, Mar del Plata. Anais... Mar del Plata, 10., Associação Argentina de Agrometeorologia, 2004. v. 1, p. 1-10.

GOMES, E.N.; ESCOBEDO, J.F.; OLIVEIRA, A.P.; SOARES, J. Evolução diurna e anual da radiação direta na incidência. Avances en Energías Renovables y Medio Ambiente, Salta, v.10, n.11, p.129-136, 2006.

LULU, J.; CASTRO, J. D. de; PEDRO JÚNIOR, M. J. Efeito do microclima na qualidade da uva de mesa 'Romana' (A 1105) cultivada sob cobertura plástica. Revista Brasileira de Fruticultura, Jaboticabal, v. 27, n. 3, p. 422-425, 2005.

MARTIN, T. N.; STORCK, L.; DOURADO NETO, D. Simulação estocástica da radiação fotossinteticamente ativa e da temperatura do ar por diferentes métodos. Pesquisa Agropecuária Brasileira, Brasília, v. 42, n. 9, p. 1.211-1.219, 2007.

MARTIN, T. N.; DOURADO NETO, D.; STORCK, L.; BURAUEL, P.; SANTOS, E. A. Regiões homogêneas e tamanho de amostra para atributos do clima no Estado de São Paulo, Brasil. Ciência Rural, Santa Maria, v. 38, n. 3, p. 690-697, 2008.

MOREIRA, M. A.; RUDORFF, B. F. T.; FELICIO, J. C.; FREITAS, J. G. de; TARGA, M. dos S. Variação espectral e eficiência do uso da radiação fotossinteticamente ativa em ensaio com genótipos de trigo. Bragantia, Campinas, v. 64, n. 3, p. 331-338, 2005. 
OLIVEIRA, E. C. de; LAMEIRA, O. A.; SOUSA, F. I. B. de; SILVA, R. J. F. Estrutura foliar de curauá em diferentes intensidades de radiação fotossinteticamente ativa. Pesquisa Agropecuária Brasileira, Brasília, v. 43, n. 2, p. 163-169, 2008.

PEZZOPANE, J. E. M.; OLIVEIRA, P. C.; REIS, E. F.; LIMA, J. S. S. Alterações microclimáticas causadas pelo uso de tela plástica. Engenharia Agrícola, Jaboticabal, v. 24, n. 1, p. 9-15, 2004.

RICIERI, R. P.; ESCOBEDO, J. F. Radiação solar global e difusa em estufas túneis com cobertura de polietileno. Energia na Agricultura, Botucatu, v. 11, p. 15-37, 1996.

SCARANARI, C.; LEAL, P. A. M.; PELLEGRINO, G. Q. Estudo de simulações de microclimas em casas de vegetação visando à aclimatação de mudas micropropagadas de bananeira cv Grande Naine. Revista Brasileira de Fruticultura, Jaboticabal, v. 30, n. 4, p. 1.001-1.008, 2008.

SILVA JUNIOR, J. de A.; COSTA, R. F. da; COSTA, A. C. L. da; GONÇALVES, P. H. L.; BRAGA, A. P.; MALHI, Y. S.; ARAGÃO, L. E. O. C de; MEIR, P. Sazonalidade de elementos meteorológicos em ecossistema de manguezal na região equatorial, Pará, Brasil. Revista Brasileira de Meteorologia, São José dos Campos, v. 21, n. 3b, p. 241-247, 2006.

STEIDLE NETO, A. J.; RIBEIRO, A.; ZOLNIER, S.; LEITE, F. P. Variabilidade sazonal da relação entre a radiação fotossinteticamente ativa e a radiação global na bacia do Rio Doce, Estado de Minas Gerais. Acta Scientiarum. Agronomy, Maringá, v. 28, n. 3, p. 427-431, 2006. 